\title{
Mapping the EQ-5D-5L Utility Scores: A Pilot Study in Orthopaedic Patients
}

\author{
Man Hung*, Christine Cheng, Shirley D. Hon, Jerry Bounsanga \\ Orthopaedic Surgery and Operation, School of Medicine, University of Utah, Salt Lake City, UT, USA \\ Email: Man.Hung@hsc.utah.edu
}

Received 20 February 2015; accepted 31 March 2015; published 3 April 2015

Copyright (C) 2015 by authors and Scientific Research Publishing Inc.

This work is licensed under the Creative Commons Attribution International License (CC BY). http://creativecommons.org/licenses/by/4.0/

cC) (i) Open Access

\begin{abstract}
Objective: The purpose of this study is to investigate whether the LE CAT, PROMIS PF CAT, Depression CAT, or Pain CAT can be used as a proxy for the EQ-5D-5L. Background: Patient-reported outcome measures have become vital tools for physicians to understand the effectiveness and value of treatment and care. Methods: This study was conducted in 2012 with 116 patients that took the EQ-5D-5L and a number of patient-reported outcome instruments in a university orthopaedic clinic. Regression analyses were conducted to predict EQ-5D-5L index scores from the LE CAT, PROMIS PF CAT, Depression CAT, and Pain CAT. Results: All predictors, separately or combined, significantly predicted the EQ-5D-5L index scores $(p<0.0001)$. The LE CAT was the best predictor; it alone accounted for $37 \%$ of the variability in the EQ-5D-5L. When combining patient-reported outcome measures, the best predicting model was the one consisting of the LE CAT, Depression CAT and Pain CAT; they explained for $43.9 \%$ of the variance in EQ-5D-5L. Conclusions: The findings provide encouraging news that the LE CAT, PF CAT, Depression CAT and Pain CAT can be used alone or in combination as a proxy for the EQ-5D-5L. Researchers have the options of using these patient-reported outcome measures for economic evaluations and medical intervention studies.
\end{abstract}

Keywords

PROMIS, LE CAT, Physical Function, Depression, Pain, EQ-5D-5L, Orthopaedics

\section{Introduction}

Assessment of health outcomes has progressed greatly in the past decade with the introduction of new tools that rely on advanced statistical methodologies. Patient-reported outcome measures have become vital tools for physicians to understand the effectiveness and value of treatment and care. Physicians traditionally relied mainly on

*Corresponding author. 
clinical measures to assess and compare the effectiveness of treatment. Even though clinical measures provide a great deal of information to the physician and patient, they do not necessarily reflect how a patient feels in their everyday life [1]. There is some evidence that there is not a very strong correlation between clinical and patient-reported outcome measures and therefore, measures should be used in conjunction with each other when assessing the condition of patients [2]-[4]. As a result, physicians are increasingly relying on the integration of clinical measures and patient-reported outcome measures to assess treatment outcomes and interventions.

There is not a universal patient-reported outcome measure that is widely used by all physicians. Instrument selection varies depending on the physician's background and familiarity with the tools and their areas of specialization. The Medical Outcomes General Health Survey and the European Quality of Life-5 Dimensions (EQ-5D) are very popular among physicians to measure health outcomes and are utilized for quality-adjusted life-years in cost-utility analyses. Other instruments such as the National Institute of Health sponsored Patient-Reported Outcomes Measurement Information System (PROMIS) Physical Function (PF), Computerized Adaptive Test (CAT), and the Lower Extremity (LE) CAT have demonstrated desirable psychometric properties and are increasing applications in clinical studies. Utilizing item response theory, the PROMIS PF item bank is developed, which includes 124 items measuring upper extremity, lower extremity, central, axial, and instrumental activities of daily living [5]. The PF CAT draws items from the PF item bank for test administration. It has been demonstrated to exhibit validity and reliability in the orthopaedic population and for patients undergoing foot and ankle surgery [6]. A recent study suggested that less instrument bias could be accomplished by developing a lower extremity instrument from the PF item bank. As a result, the 79-item LE CAT item bank was developed in an effort to specifically target patients with lower extremity conditions [5] [7]. The PROMIS also includes item banks that address depression and pain. When considering cost-utility analyses, the EQ-5D is often adopted and its preference-based index scores are used for estimation of quality-adjusted life years for economic evaluation. Its index scores are derived from measures across five health dimensions: mobility, self-care, usual activities, pain/discomfort, and anxiety/depression. The EQ-5D can be a very useful tool for clinicians and researchers. The EQ-5D-3L (three response levels) has been shown to be a valid and reliable instrument in many contexts, but it has also received scrutiny for lacking sensitivity and failing to capture disease specific conditions [8]-[12]. In response, the European Quality of Life Group developed a five response level version of the EQ-5D, the European Quality of Life-5 Dimensions 5 Response Levels (EQ-5D-5L). Compared to the previous version with three response levels, the EQ-5D-5L has demonstrated a lower ceiling effect [11], good convergent validity [12], and content and face validity [8].

Researchers in the past have conducted studies to map preference-based index scores from general health outcome profile measures [13]-[17]. Several studies have been published detailing the mapping of the EQ-5D-3L index scores from the Medical Outcomes General Health Survey using large national samples [18]-[21]. Recently, scores from the PROMIS global item bank and selected domain item banks have also been mapped to the EQ-5D-3L on the general population and a few clinical samples [22]. Given the increasing utilization of patient-reported outcome measures and the application of PROMIS instruments in clinical settings and in research studies, mapping of the health preference scores from the patient-reported outcome measures can be very useful and these scores can be used in cost-effectiveness studies when health preference measures are unavailable. To our knowledge, there is no existing published study to date reporting the mapping of EQ-5D-5L from any patient-reported outcome measures or health profiles.

The purpose of this study is to investigate whether the LE CAT, PF CAT, PROMIS Depression, and/or PROMIS Pain measures can be mapped from the EQ-5D-5L. In doing so, we are ultimately interested if the scores from any of these patient-reported outcome instruments can be used as a proxy of health preference scores when health preference assessments such as EQ-5D are absent.

\section{Methods}

\subsection{Data Collection}

In 2012, data were collected from a large university orthopaedic center with patients that were 18 years old or older who came to visit for lower extremity orthopaedic problems. This university orthopaedic center had over 90,000 total patient visits and over 3,000 total surgeries per year. At the end of their clinic visit, patients were asked to voluntarily complete the EQ-5D-5L, the LE CAT, the PF CAT, the PROMIS Depression CAT, and the PROMIS Pain CAT instruments (See Appendices 1-5) along with a few demographic questions. These ques- 
tionnaires were administered electronically using tablet computers. The order of questionnaire administration was completely random in efforts to minimize potential bias from test administration. Institutional Review Board approval was obtained prior to the study. Medical and research staff obtained informed consent from the patients and the rights of the subjects were protected. The final sample consisted of 116 patients.

\subsection{Analytic Approach}

Descriptive statistics were conducted to summarize patient demographic and instrument characteristics. All CAT scores used in the analyses were $\mathrm{T}$ scores, which had a mean of 50 and standard deviation of 10. The EQ-5D-5L utility index scores were derived and converted from the responses to the five dimensions of the EQ-5D questionnaire. To examine the association between the patient-reported outcome measures (LE CAT, PF CAT, Depression CAT, and Pain CAT) and the EQ-5D-5L index value, we examined the Pearson product-moment correlations among these instruments. To investigate whether the patient-reported outcome measures can be mapped from the EQ-5D-5L, we applied ordinary least square linear regression analyses to predict EQ-5D-5L from the patient-reported outcome measures. Six regression models were conducted to assess the individual contribution of each of the patient-reported outcome measures and the combined contribution of the patient-reported outcome measures. Model 1 included only the LE CAT as the predictor of EQ-5D-5L; model 2 included only the PF CAT as the predictor; model 3 included only the Depression CAT as the predictor; model 4 included only the Pain CAT as the predictor; model 5 included the LE CAT, Depression CAT and Pain CAT as the predictors; and model 6 included the PF CAT, Depression CAT and Pain CAT as predictors. Intraclass correlation coefficients were computed to compare the actual EQ-5D-5L index scores with the estimated EQ-5D-5L index scores from the predictors in the regression models. To further understand the sensitivity of these patient-reported outcome measures as well as the EQ-5D-5L across health conditions, we conducted independent samples t-tests to see if there were significant score differences between patients who: (1) have numb feet versus do not have numb feet, and (2) have diabetes versus do not have diabetes.

A sample size of 116 patients would achieve $99.7 \%$ power to detect an $R^{2}$ of 0.200 attributed to 3 independent variables using an F-Test with a significance level of 0.05 .

\section{Results}

\subsection{Demographic Characteristics}

The study sample consisted of 55\% female, 93.4\% white, with a mean age of 44 years old (range from 18 to 80 ). About $9 \%$ of the participants identified as Hispanic or Latino. About $66 \%$ of the participants completed some college courses. Approximately $64 \%$ of the participants said they did not drink alcohol, $86 \%$ did not smoke, and $94 \%$ reported that they did not have diabetes. 51\% reported that there was another area that limited their current activities besides their foot and ankle problem. About $23 \%$ of the participants stated that their feet were numb and $8 \%$ reported that they had rheumatoid arthritis.

\subsection{Instrument Characteristics}

Descriptive summary (range, minimum, maximum, mean, standard deviation) of the scores from all of the instruments was presented in Table 1. All these instruments were moderately to highly correlate with each other (See Table 2). The highest correlation between the health preference measure and the patient-reported outcome measures was between the EQ-5D-5L and the LE CAT, $r(116)=0.612, \mathrm{p}<0.0001$. As expected, the PRO instruments were moderately to highly correlate with each other. The highest correlation among the instruments was between the LE CAT and the PF CAT, $r(116)=0.801, \mathrm{p}<0.0001$.

\subsection{Regression Analyses}

To predict the EQ-5D-5L index scores, six linear regression models were run and their results were summarized in Table 3. The PF CAT and the LE CAT were not included in the same model because they were highly correlated. All the predictors separately or combined significantly predicted the EQ-5D-5L scores $(\mathrm{p}<0.0001)$. The LE CAT was the best individual predictor; it alone accounted for $37 \%$ of the variability in the EQ-5D-5L. When combining patient-reported outcome measures, the best predicting model was the one consisting of the LE CAT, 
Table 1. Descriptive statistics of the instruments.

\begin{tabular}{cccccc}
\hline Instruments & Range & Minimum & Maximum & Mean & Std. Dev. \\
\hline EQ-5D-5L & 0.88 & 0.12 & 1.00 & 0.68 & 0.18 \\
LE CAT & 68.10 & 12.70 & 80.80 & 52.92 & 13.93 \\
PF CAT & 48.10 & 22.20 & 70.30 & 40.14 & 7.62 \\
Depression CAT & 45.60 & 34.20 & 79.80 & 51.36 & 9.91 \\
Pain CAT & 36.70 & 38.60 & 75.30 & 61.51 & 7.29 \\
\hline
\end{tabular}

Table 2. Pearson product-moment correlations among the instruments.

\begin{tabular}{cccccc}
\hline Instruments & EQ-5D-5L & LE CAT & PF CAT & Depression CAT & Pain CAT \\
\hline EQ-5D-5L & 1.000 & & & & \\
LE CAT & 0.612 & 1.000 & & & \\
PF CAT & 0.538 & 0.801 & 1.000 & 1.000 & 1.000 \\
Depression CAT & -0.446 & -0.393 & -0.349 & 0.474 & -0.406 \\
Pain CAT & -0.502 & -0.476 & & & \\
\hline
\end{tabular}

Table 3. Predicting the EQ-5D-5L index scores.

\begin{tabular}{cccc}
\hline Models & Predictors & $\mathrm{R}^{2}$ & Adjusted R $^{2}$ \\
\hline 1 & LE CAT & 0.375 & 0.370 \\
2 & PF CAT & 0.289 & 0.283 \\
3 & Depression CAT & 0.199 & 0.192 \\
4 & Pain CAT & 0.252 & 0.245 \\
5 & LE CAT, Depression CAT \& Pain CAT & 0.454 & 0.439 \\
6 & PF CAT, Depression CAT \& Pain CAT & 0.413 & 0.398 \\
\hline
\end{tabular}

Depression CAT and Pain CAT; they explained for $43.9 \%$ of the variance in EQ-5D-5L. Table 4 presents the actual EQ-5D-5L index scores versus the predicted EQ-5D-5L index scores from the six regression models. All predicted scores were essentially identical to the actual scores $(\mathrm{p}>0.99)$.

To assess the degree of correlation between the actual EQ-5D-5L scores and the predicted EQ-5D-5L scores from the regression models, we computed the intraclass correlations (See Table 5). The intraclass correlation for the LE CAT was 0.708, the highest among the individual predictors. The intraclass correlation for the LE CAT, Depression CAT, and Pain CAT combined was 0.770. The intraclass correlation for the PF CAT, Depression CAT, Pain CAT combined was 0.740 .

\subsection{Instrument Scores by Health Conditions}

Between participants that did and did not have numb feet, only the LE CAT showed significant difference in mean scores $(p=0.002)$ (See Table 6). When investigating participants that did and did not have diabetes, both the LE CAT $(p=0.01)$ and the PF CAT $(p=0.02)$ demonstrated that there was a significant difference in scores.

\section{Discussion}

In this study, we investigated whether the EQ-5D-5L preference scores could be mapped from the LE CAT, PF CAT, PROMIS Depression CAT, and/or PROMIS Pain CAT measures using regression estimation methods. We examined the correlations between the instruments, the differences in scores by health conditions, the variance 
Table 4. Mean actual and predicted EQ-5D-5L index scores from various PRO measures.

\begin{tabular}{ccc}
\hline & EQ-5D-5L scores & $($ SE) \\
Actual & 0.675070 & $(0.016749)$ \\
Predicted from & & $(0.010257)$ \\
LE CAT & 0.675069 & $(0.009004)$ \\
PF CAT & 0.675069 & $(0.007464)$ \\
Depression CAT & 0.675069 & $(0.008401)$ \\
Pain CAT & 0.675069 & $(0.011284)$ \\
LE CAT, Depression CAT \& Pain CAT & 0.675069 & $(0.010769)$ \\
\hline
\end{tabular}

Table 5. Intraclass correlation correlations (ICC) of the actual EQ-5D-5L index scores with the predicted EQ-5D-5L index scores from various PRO measures.

\begin{tabular}{ccc}
\hline Predicted EQ-5D-5L index scores from & ICC & $95 \%$ CI \\
\hline LE CAT & 0.708 & {$[0.577,0.798]$} \\
PF CAT & 0.621 & {$[0.452,0.738]$} \\
Depression CAT & 0.500 & {$[0.277,0.654]$} \\
Pain CAT & 0.576 & {$[0.386,0.706]$} \\
LE CAT, Depression CAT \& Pain CAT & 0.770 & {$[0.668,0.841]$} \\
PF CAT, Depression CAT \& Pain CAT & 0.740 & {$[0.624,0.820]$} \\
\hline
\end{tabular}

Table 6. Mean score differences by health condition.

\begin{tabular}{ccc}
\hline & Numb feet/No numb feet & With diabetes/Without diabetes \\
\cline { 2 - 3 } Instruments & Score difference (p-value, 2-tailed) & Score difference (p-value, 2-tailed) \\
\hline EQ-5D-5L & $0.0556040(0.162)$ & $0.0116280(0.087)$ \\
LE CAT & $8.3926758(0.002)^{*}$ & $13.9024902(0.001)^{*}$ \\
PF CAT & $3.1059093(0.063)$ & $6.8559633(0.002)^{*}$ \\
Depression CAT & $1.1560133(0.598)$ & $1.6158585(0.678)$ \\
Pain CAT & $2.9609238(0.064)$ & $0.4800786(0.867)$ \\
\hline
\end{tabular}

Note: ${ }^{*} \mathrm{p}<0.05$.

accounted for when predicting EQ-5D-5L scores, and intraclass correlations between the actual and predicted EQ-5D-5L scores.

All of the instruments were significantly correlated with each other, with the LE CAT and the PF CAT having the highest correlation, which was expected. Given that the LE CAT had the highest correlation with the EQ-5D-5L index scores $(r=0.612)$, this suggested that the LE CAT could be best mapped to the EQ-5D-5L. The correlations of the EQ-5D-5L with the PF CAT, the Depression CAT and the Pain CAT were all relatively high, at $r=0.538,-0.446$, and -0.502 respectively.

We conducted regression analyses to assess the effects of the patient-reported outcome measures on the EQ-5D-5L index scores. We found that the LE CAT scores alone accounted for $37 \%$ of the variance in the EQ-5D-5L scores, which was much more than we expected. The PF CAT, Depression CAT, and Pain CAT, each alone predicted $28.3 \%, 19.2 \%$, and $24.5 \%$ of the variance in the EQ-5D-5L respectively. When including 
the Depression CAT and the Pain CAT scores with the LE CAT and PF CAT measures in separate models, the variance explained increased to over $40 \%$ for the PF CAT and $45 \%$ for the LE CAT. These findings demonstrated that if we were going to pick a single instrument as a proxy for the EQ-5D-5L preference scores in this patient population, it would be the LE CAT. When including more than one patient-reported outcome measures to predict the EQ-5D, the LE CAT, the Depression CAT, and the Pain CAT accounted for the most of the variance in the models. While adopting a combination of patient-reported outcome measures did not minimize the number of items needed, it provided physicians more options for instruments that can be used when health preference assessments were unavailable.

We also examined the intraclass correlation to assess whether the EQ-5D-5L index scores can be accurately estimated by the patient-reported outcome measures. Findings indicate that the patient-reported outcome measures can accurately predict the EQ-5D-5L index scores. Alone, the PF CAT had an ICC of 0.621 and the LE CAT had an intraclass correlation of 0.708 . This again shows that the LE CAT is a better proxy of the EQ-5D5L, but the PF CAT also does a very good job. When we examine the intraclass correlations of the PF CAT and the LE CAT combined with the Depression CAT and Pain CAT, the intraclass correlations are largely demonstrating good agreement. The LE CAT with the Depression CAT and Pain CAT had a slightly better intraclass correlation of 0.770 compared to 0.740 of the PF CAT with the Depression and Pain CAT. As a result, we would assert that the LE CAT, Depression CAT, and Pain CAT together are a good approximation of the EQ-5D-5L preference index. If clinicians or researchers were only interested in using a single patient-reported outcome measure, the LE CAT would be the best proxy choice for EQ-5D-5L.

Finally, we tested for score differences for each instrument (LE CAT, PF CAT, Depression CAT, Pain CAT, EQ-5D-5L) with patients who had two different types of health conditions. Most of the instruments were not sensitive enough to demonstrate significant mean score differences in measuring patients with numb feet and diabetes. Only the LE CAT was able to significantly discriminate patients with numb feet versus patients without numb feet. Both the LE CAT and the PF CAT were able to significantly discriminate patients with diabetes and without diabetes. This finding spoke to the possibility that the LE CAT or the PF CAT could be a potentially better tool for conducting cost-effectiveness research or economic analyses.

\section{Conclusion}

Taken together, our results demonstrate that the LE CAT or a combination of the LE CAT with the Depression CAT and Pain CAT can be a useful proxy for the EQ-5D-5L preference index. Physicians or researchers interested in conducting cost-utility analyses have the choice of using either the EQ-5D-5L, the LE CAT, the PF CAT, the Depression CAT, or the Pain CAT individually or in combination. Further research is needed to confirm the results of this study in a larger patient population.

\section{Acknowledgements}

This investigation was supported by the Department of Orthopaedic, University of Utah and the Center for Outcomes Research and Assessment, with funding in part from the National Institute of Arthritis and Musculoskeletal and Skin Diseases of the National Institutes of Health under Award Number U01AR067138. The content is solely the responsibility of the authors and does not necessarily represent the official views of the National Institutes of Health.

\section{References}

[1] Deshpande, P.R., Rajan, S., Sudeepthi, B.L. and Abdul Nazir, C.P. (2011) Patient-Reported Outcomes: A New Era in Clinical Research. Perspectives in Clinical Research, 2, 137-144. http://dx.doi.org/10.4103/2229-3485.86879

[2] Myers, A.M., Holliday, P.J., Harvey, K.A. and Hutchinson, K.S. (1993) Functional Performance Measures: Are They Superior to Self-Assessments? Journal of Gerontology, 48, M196-M206. http://dx.doi.org/10.1093/geronj/48.5.M196

[3] Hidding, A., van Santen, M., De Klerk, E., Gielen, X., Boers, M., Geenen, R., Vlaeyen, J., Kester, A. and van der Linden, S. (1994) Comparison between Self-Report Measures and Clinical Observations of Functional Disability in Ankylosing Spondylitis, Rheumatoid Arthritis and Fibromyalgia. The Journal of Rheumatology, 21, 818-823.

[4] Reuben, D.B., Valle, L.A., Hays, R.D. and Siu, A.L. (1995) Measuring Physical Function in Community-Dwelling Older Persons: A Comparison of Self-Administered, Interviewer-Administered, and Performance-Based Measures. Journal of the American Geriatrics Society, 43, 17-23. 
[5] Hung, M., Clegg, D.O., Greene, T. and Saltzman, C.L. (2011) Evaluation of the PROMIS Physical Function Item Bank in Orthopaedic Patients. Journal of Orthopaedic Research, 29, 947-953. http://dx.doi.org/10.1002/jor.21308

[6] Hung, M., Baumhauer, J.F., Latt, L.D., Saltzman, C.L., SooHoo, N.F., Hunt, K.J., and National Orthopaedic Foot and Ankle Outcomes Research Network (2013) Validation of PROMIS ${ }^{\circledR}$ Physical Function Computerized Adaptive Tests for Orthopaedic Foot and Ankle Outcome Research. Clinical Orthopaedics and Related Research ${ }^{\circledR}$ 471, 3466-3474. http://dx.doi.org/10.1007/s11999-013-3097-1

[7] Hung, M., Clegg, D.O., Greene, T., Weir, C. and Saltzman, C.L. (2012) A Lower Extremity Physical Function Computerized Adaptive Testing Instrument for Orthopaedic Patients. Foot \& Ankle International, 33, 326-335. http://dx.doi.org/10.3113/FAI.2012.0326

[8] Herdman, M., Gudex, C., Lloyd, A., Janssen, M.F., Kind, P., Parkin, D., Bonsel, G. and Badia, X. (2011) Development and Preliminary Testing of the New Five-Level Version of EQ-5D (EQ-5D-5L). Quality of Life Research, 20, 1727-1736. http://dx.doi.org/10.1007/s11136-011-9903-x

[9] Janssen, M.F., Birnie, E. and Bonsel, G.J. (2008) Quantification of the Level Descriptors for the Standard EQ-5D Three-Level System and a Five-Level Version According to Two Methods. Quality of Life Research, 17, 463-473. http://dx.doi.org/10.1007/s11136-008-9318-5

[10] Janssen, M.F., Pickard, A.S., Golicki, D., Gudex, C., Niewada, M., Scalone, L., Swinburn, P. and Busschbach, J. (2013) Measurement Properties of the EQ-5D-5L Compared to the EQ-5D-3L across Eight Patient Groups: A Multi-Country Study. Quality of Life Research, 22, 1717-1727. http://dx.doi.org/10.1007/s11136-012-0322-4

[11] Pickard, A.S., De Leon, M.C., Kohlmann, T., Cella, D. and Rosenbloom, S. (2007) Psychometric Comparison of the Standard EQ-5D to a 5 Level Version in Cancer Patients. Medical Care, 45, 259-263. http://dx.doi.org/10.1097/01.mlr.0000254515.63841.81

[12] Tran, B.X., Ohinmaa, A. and Nguyen, L.T. (2012) Quality of Life Profile and Psychometric Properties of the EQ-5D-5L in HIV/AIDS Patients. Health and Quality of Life Outcomes, 10, 132. http://dx.doi.org/10.1186/1477-7525-10-132

[13] Brazier, J., Roberts, J. and Deverill, M. (2002) The Estimation of a Preference-Based Measure of Health from the SF-36. Journal of Health Economics, 21, 271-292. http://dx.doi.org/10.1016/S0167-6296(01)00130-8

[14] Brazier, J.E. and Roberts, J. (2004) The Estimation of a Preference-Based Measure of Health from the SF-12. Medical Care, 42, 851-859. http://dx.doi.org/10.1097/01.mlr.0000135827.18610.0d

[15] Cortesi, P.A., Scalone, L., Belisari, A., Bonamonte, D., Cannavo, S.P., Cristaudo, A., De Pità, O., Gallo, R., Giannetti, A., Gola, M., Pigatto, P.D. and Mantovani, L.G. (2014) Cost and Quality of Life in Patients with Severe Chronic Hand Eczema Refractory to Standard Therapy with Topical Potent Corticosteroids. Contact Dermatitis, 70, 158-168. http://dx.doi.org/10.1111/cod.12130

[16] Erickson, P. (1998) Evaluation of a Population-Based Measure of Quality of Life: The Health and Activity Limitation Index (HALex). Quality of Life Research, 7, 101-114. http://dx.doi.org/10.1023/A:1008897107977

[17] Shaw, J.W., Johnson, J.A. and Coons, S.J. (2005) US Valuation of the EQ-5D Health States: Development and Testing of the D1 Valuation Model. Medical Care, 43, 203-220. http://dx.doi.org/10.1097/00005650-200503000-00003

[18] Gray, A.M., Rivero-Arias, O. and Clarke, P.M. (2006) Estimating the Association between SF-12 Responses and EQ-5D Utility Values by Response Mapping. Medical Decision Making, 26, 18-29. http://dx.doi.org/10.1177/0272989X05284108

[19] Lawrence, W.F. and Fleishman, J.A. (2004) Predicting EuroQoL EQ-5D Preference Scores from the SF-12 Health Survey in a Nationally Representative Sample. Medical Decision Making, 24, 160-169. http://dx.doi.org/10.1177/0272989X04264015

[20] Nan, L., Johnson, J.A., Shaw, J.W. and Coons, S.J. (2007) A Comparison of EQ-5D Index Scores Derived from the US and UK population-Based Scoring Functions. Medical Decision Making, 27, 321-326. http://dx.doi.org/10.1177/0272989X07300603

[21] Sullivan, P.W. and Ghushchyan, V. (2006) Mapping the EQ-5D Index from the SF-12: US General Population Preferences in a Nationally Representative Sample. Medical Decision Making, 26, 401-409. http://dx.doi.org/10.1177/0272989X06290496

[22] Revicki, D.A., Kawata, A.K., Harnam, N., Chen, W.-H., Hays, R.D. and Cella, D. (2009) Predicting EuroQol (EQ-5D) Scores from the Patient-Reported Outcomes Measurement Information System (PROMIS) Global Items and Domain Item Banks in a United States Sample. Quality of Life Research, 18, 783-791. http://dx.doi.org/10.1007/s11136-009-9489-8 
Appendix 1. European quality of Life-5 dimensions (EQ-5D).

\begin{tabular}{|c|c|c|}
\hline Concept & Question & Coded Level \\
\hline & $\begin{array}{l}\text { Under each heading, please tick the ONE box that } \\
\text { best describes your health TODAY }\end{array}$ & \\
\hline \multicolumn{3}{|l|}{ Mobility } \\
\hline & I have no problems in walking about & 1 \\
\hline & I have slight problems in walking about & 2 \\
\hline & I have moderate problems in walking about & 3 \\
\hline & I have severe problems in walking about & 4 \\
\hline & I am unable to walk about & 5 \\
\hline \multicolumn{3}{|l|}{ Self-Care } \\
\hline & I have no problems washing or dressing myself & 1 \\
\hline & I have slight problems washing or dressing myself & 2 \\
\hline & I have moderate problems washing or dressing myself & 3 \\
\hline & I have severe problems washing or dressing myself & 4 \\
\hline & I am unable to wash or dress myself & 5 \\
\hline \multicolumn{3}{|c|}{$\begin{array}{l}\text { Usual Activities (e.g. work, study, } \\
\text { housework, family or leisure activities) }\end{array}$} \\
\hline & I have no problems doing my usual activities & 1 \\
\hline & I have slight problems doing my usual activities & 2 \\
\hline & I have moderate problems doing my usual activities & 3 \\
\hline & I have severe problems doing my usual activities & 4 \\
\hline & I am unable to do my usual activities & 5 \\
\hline \multicolumn{3}{|c|}{ Pain/Discomfort } \\
\hline & I have no pain or discomfort & 1 \\
\hline & I have slight pain or discomfort & 2 \\
\hline & I have moderate pain or discomfort & 3 \\
\hline & I have severe pain or discomfort & 4 \\
\hline & I have extreme pain or discomfort & 5 \\
\hline \multicolumn{3}{|c|}{ Anxiety/Depression } \\
\hline & I am not anxious or depressed & 1 \\
\hline & I am slightly anxious or depressed & 2 \\
\hline & I am moderately anxious or depressed & 3 \\
\hline & I am severely anxious or depressed & 4 \\
\hline & I am extremely anxious or depressed & 5 \\
\hline
\end{tabular}


Appendix 2. Lower extremity (LE) physical function CAT item bank.

\begin{tabular}{|c|c|c|}
\hline Item Number & ID* & Items** \\
\hline 1 & PFA1 & $\begin{array}{l}\text { Does your health now limit you in doing vigorous activities, such as running, lifting heavy objects, } \\
\text { participating in strenuous sports? }\end{array}$ \\
\hline 2 & PFA3 & Does your health now limit you in bending, kneeling, or stooping? \\
\hline 3 & PFA4 & $\begin{array}{l}\text { Does your health now limit you in doing heavy work around the house like scrubbing floors, } \\
\text { or lifting or moving heavy furniture? }\end{array}$ \\
\hline 4 & PFA5 & Does your health now limit you in lifting or carrying groceries? \\
\hline 5 & PFA6 & Does your health now limit you in bathing or dressing yourself? \\
\hline 6 & PFA7 & $\begin{array}{l}\text { How much do physical health problems now limit your usual physical activities } \\
\text { (such as walking or climbing stairs)? }\end{array}$ \\
\hline 7 & PFA8 & Are you able to move a chair from one room to another? \\
\hline 8 & PFA9 & Are you able to bend down and pick up clothing from the floor? \\
\hline 9 & PFA10 & Are you able to stand for one hour? \\
\hline 10 & PFA11 & Are you able to do chores such as vacuuming or yard work? \\
\hline 11 & PFA12 & Are you able to push open a heavy door? \\
\hline 12 & PFA13 & Are you able to exercise for an hour? \\
\hline 13 & PFA14 & Are you able to carry a heavy object (over 10 pounds)? \\
\hline 14 & PFA15 & Are you able to stand up from an armless straight chair? \\
\hline 15 & PFA19 & Are you able to run or jog for two miles? \\
\hline 16 & PFA21 & Are you able to go up and down stairs at a normal pace? \\
\hline 17 & PFA23 & Are you able to go for a walk of at least 15 minutes? \\
\hline 18 & PFA25 & Are you able to do yard work like raking leaves, weeding, or pushing a lawn mower? \\
\hline 19 & PFA29 & Are you able to pull heavy objects (10 pounds) towards yourself? \\
\hline 20 & PFA30 & Are you able to step up and down curbs? \\
\hline 21 & PFA31 & Are you able to get up off the floor from lying on your back without help? \\
\hline 22 & PFA32 & Are you able to stand with your knees straight? \\
\hline 23 & PFA33 & Are you able to exercise hard for half an hour? \\
\hline 24 & PFA37 & Are you able to stand for short periods of time? \\
\hline 25 & PFA39 & Are you able to run at a fast pace for two miles? \\
\hline 26 & PFA41 & Are you able to squat and get up? \\
\hline 27 & PFA42 & Are you able to carry a laundry basket up a flight of stairs? \\
\hline 28 & PFA45 & Are you able to get out of bed into a chair? \\
\hline 29 & PFA49 & Are you able to bend or twist your back? \\
\hline 30 & PFA51 & Are you able to sit on the edge of a bed? \\
\hline 31 & PFA53 & Are you able to run errands and shop? \\
\hline 32 & PFA56 & Are you able to get in and out of a car? \\
\hline 33 & PFB1 & $\begin{array}{l}\text { Does your health now limit you in doing moderate work around the house like vacuuming, } \\
\text { sweeping floors or carrying in groceries? }\end{array}$ \\
\hline 34 & PFB3 & Does your health now limit you in putting a trash bag outside? \\
\hline 35 & PFB5 & Does your health now limit you in hiking a couple of miles on uneven surfaces, including hills? \\
\hline 36 & PFB7 & $\begin{array}{l}\text { Does your health now limit you in doing strenuous activities such as backpacking, skiing, playing tennis, } \\
\text { bicycling or jogging? }\end{array}$ \\
\hline 37 & PFB8 & Are you able to carry two bags filled with groceries 100 yards? \\
\hline 38 & PFB9 & Are you able to jump up and down? \\
\hline 39 & PFB10 & Are you able to climb up five steps? \\
\hline 40 & PFB11 & Are you able to wash dishes, pots, and utensils by hand while standing at a sink? \\
\hline
\end{tabular}


Continued

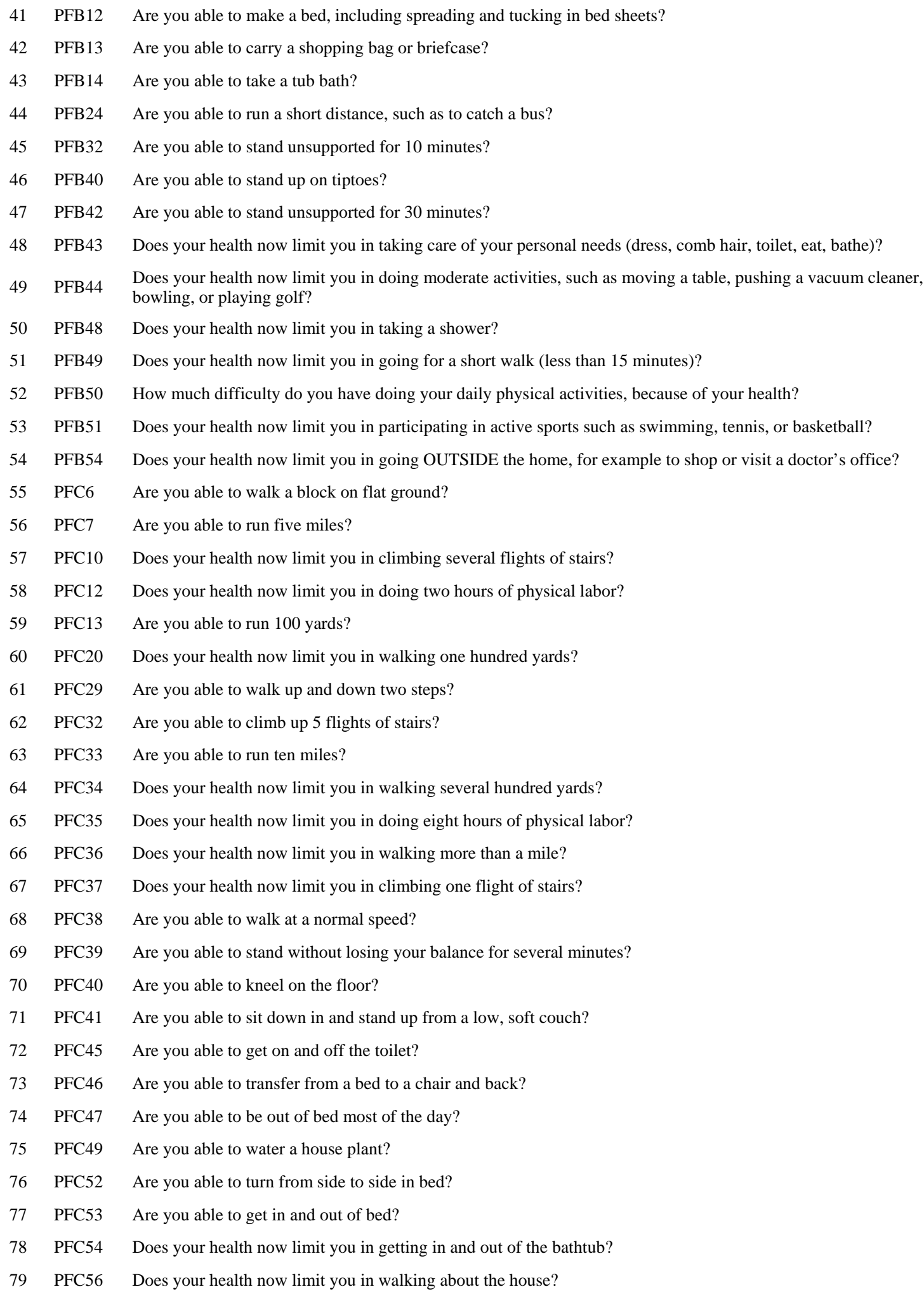

*The original item identifier from the PROMIS item bank; **Response options for questions 1 - 6; 33 - 36; 48 - 51; 53 - 54; 57 - 58; $60 ; 64$ - 67; 78 79: 1 = Cannot do; 2 = Quite a lot; 3 = Somewhat; 4 = Very little; 5 = Not at all; for questions 7 - 32; 37 - 47; 52; 55 - 56; 59; 61 - 63; 68 - 77: 1 = Unable to do; 2 = With much difficulty; 3 = With some difficulty; 4 = With a little difficulty; 5 = Without any difficulty. 
Appendix 3. Physical function (PF) CAT item bank.

\begin{tabular}{|c|c|c|}
\hline Item Number & $\mathrm{ID} * * * *$ & Items \\
\hline $1^{*}$ & PFA10 & Are you able to stand for one hour? \\
\hline 2 & PFA11 & Are you able to do chores such as vacuuming or yard work? \\
\hline 3 & PFA12 & Are you able to push open a heavy door? \\
\hline 4 & PFA13 & Are you able to exercise for an hour? \\
\hline 5 & PFA14 & Are you able to carry a heavy object (over 10 pounds)? \\
\hline 6 & PFA15 & Are you able to stand up from an armless straight chair? \\
\hline 7 & PFA16 & Are you able to dress yourself, including tying shoelaces and doing buttons? \\
\hline 8 & PFA17 & Are you able to reach into a high cupboard? \\
\hline 9 & PFA18 & Are you able to use a hammer to pound a nail? \\
\hline 10 & PFA19 & Are you able to run or jog for two miles? \\
\hline 11 & PFA20 & Are you able to cut your food using eating utensils? \\
\hline 12 & PFA21 & Are you able to go up and down stairs at a normal pace? \\
\hline 13 & PFA22 & Are you able to open previously opened jars? \\
\hline 14 & PFA23 & Are you able to go for a walk of at least 15 minutes? \\
\hline 15 & PFA25 & Are you able to do yard work like raking leaves, weeding, or pushing a lawn mower? \\
\hline 16 & PFA28 & Are you able to open a can with a hand can opener? \\
\hline 17 & PFA29 & Are you able to pull heavy objects (10 pounds) towards yourself? \\
\hline 18 & PFA30 & Are you able to step up and down curbs? \\
\hline 19 & PFA31 & Are you able to get up off the floor from lying on your back without help? \\
\hline 20 & PFA32 & Are you able to stand with your knees straight? \\
\hline 21 & PFA33 & Are you able to exercise hard for half an hour? \\
\hline 22 & PFA34 & Are you able to wash your back? \\
\hline 23 & PFA35 & Are you able to open and close a zipper? \\
\hline 24 & PFA36 & Are you able to put on and take off a coat or jacket? \\
\hline 25 & PFA37 & Are you able to stand for short periods of time? \\
\hline 26 & PFA38 & Are you able to dry your back with a towel? \\
\hline 27 & PFA39 & Are you able to run at a fast pace for two miles? \\
\hline 28 & PFA40 & Are you able to turn a key in a lock? \\
\hline 29 & PFA41 & Are you able to squat and get up? \\
\hline 30 & PFA42 & Are you able to carry a laundry basket up a flight of stairs? \\
\hline 31 & PFA43 & Are you able to write with a pen or pencil? \\
\hline 32 & PFA44 & Are you able to put on a shirt or blouse? \\
\hline 33 & PFA45 & Are you able to get out of bed into a chair? \\
\hline 34 & PFA47 & Are you able to pull on trousers? \\
\hline 35 & PFA48 & Are you able to peel fruit? \\
\hline 36 & PFA49 & Are you able to bend or twist your back? \\
\hline 37 & PFA50 & Are you able to brush your teeth? \\
\hline 38 & PFA51 & Are you able to sit on the edge of a bed? \\
\hline 39 & PFA52 & Are you able to tie your shoelaces? \\
\hline 40 & PFA53 & Are you able to run errands and shop? \\
\hline 41 & PFA54 & Are you able to button your shirt? \\
\hline 42 & PFA55 & Are you able to wash and dry your body? \\
\hline
\end{tabular}


Continued

\begin{tabular}{|c|c|c|}
\hline 43 & PFA56 & Are you able to get in and out of a car? \\
\hline 44 & PFA8 & Are you able to move a chair from one room to another? \\
\hline 45 & PFA9 & Are you able to bend down and pick up clothing from the floor? \\
\hline 46 & PFB10 & Are you able to climb up five steps? \\
\hline 47 & PFB11 & Are you able to wash dishes, pots, and utensils by hand while standing at a sink? \\
\hline 48 & PFB12 & Are you able to make a bed, including spreading and tucking in bed sheets? \\
\hline 49 & PFB13 & Are you able to carry a shopping bag or briefcase? \\
\hline 50 & PFB14 & Are you able to take a tub bath? \\
\hline 51 & PFB15 & Are you able to change the bulb in a table lamp? \\
\hline 52 & PFB16 & Are you able to press with your index finger (for example ringing a doorbell)? \\
\hline 53 & PFB17 & Are you able to put on and take off your socks? \\
\hline 54 & PFB18 & Are you able to shave your face or apply makeup? \\
\hline 55 & PFB19 & Are you able to squeeze a new tube of toothpaste? \\
\hline 56 & PFB20 & Are you able to cut a piece of paper with scissors? \\
\hline 57 & PFB21 & Are you able to pick up coins from a table top? \\
\hline 58 & PFB22 & Are you able to hold a plate full of food? \\
\hline 59 & PFB23 & Are you able to pour liquid from a bottle into a glass? \\
\hline 60 & PFB24 & Are you able to run a short distance, such as to catch a bus? \\
\hline 61 & PFB25 & Are you able to push open a door after turning the knob? \\
\hline 62 & PFB26 & Are you able to shampoo your hair? \\
\hline 63 & PFB27 & Are you able to tie a knot or a bow? \\
\hline 64 & PFB28 & Are you able to lift 10 pounds above your shoulder? \\
\hline 65 & PFB29 & Are you able to lift a full cup or glass to your mouth? \\
\hline 66 & PFB30 & Are you able to open a new milk carton? \\
\hline 67 & PFB31 & Are you able to open car doors? \\
\hline 68 & PFB32 & Are you able to stand unsupported for 10 minutes? \\
\hline 69 & PFB33 & Are you able to remove something from your back pocket? \\
\hline 70 & PFB34 & Are you able to change a light bulb overhead? \\
\hline 71 & PFB36 & Are you able to put on a pullover sweater? \\
\hline 72 & PFB37 & Are you able to turn faucets on and off? \\
\hline 73 & PFB39 & Are you able to reach and get down a 5 pound object from above your head? \\
\hline 74 & PFB40 & Are you able to stand up on tiptoes? \\
\hline 75 & PFB41 & Are you able to trim your fingernails? \\
\hline 76 & PFB42 & Are you able to stand unsupported for 30 minutes? \\
\hline 77 & PFB56 & Are you able to lift one pound (a full pint container) to shoulder level without bending your elbow? \\
\hline 78 & PFB8 & Are you able to carry two bags filled with groceries 100 yards? \\
\hline 79 & PFB9 & Are you able to jump up and down? \\
\hline 80 & PFC13 & Are you able to run 100 yards? \\
\hline 81 & PFC29 & Are you able to walk up and down two steps? \\
\hline 82 & PFC31 & Are you able to reach into a low cupboard? \\
\hline 83 & PFC32 & Are you able to climb up 5 flights of stairs? \\
\hline 84 & PFC33 & Are you able to run ten miles? \\
\hline 85 & PFC38 & Are you able to walk at a normal speed? \\
\hline
\end{tabular}


Continued

\begin{tabular}{|c|c|c|}
\hline 86 & PFC39 & Are you able to stand without losing your balance for several minutes? \\
\hline 87 & PFC40 & Are you able to kneel on the floor? \\
\hline 88 & PFC41 & Are you able to sit down in and stand up from a low, soft couch? \\
\hline 89 & PFC43 & Are you able to use your hands, such as for turning faucets, using kitchen gadgets, or sewing? \\
\hline 90 & PFC45 & Are you able to get on and off the toilet? \\
\hline 91 & PFC46 & Are you able to transfer from a bed to a chair and back? \\
\hline 92 & PFC47 & Are you able to be out of bed most of the day? \\
\hline 93 & PFC49 & Are you able to water a house plant? \\
\hline 94 & PFC51 & Are you able to wipe yourself after using the toilet? \\
\hline 95 & PFC52 & Are you able to turn from side to side in bed? \\
\hline 96 & PFC53 & Are you able to get in and out of bed? \\
\hline 97 & PFC6 & Are you able to walk a block on flat ground? \\
\hline 98 & PFC7 & Are you able to run five miles? \\
\hline $99 * *$ & PFA1 & $\begin{array}{l}\text { Does your health now limit you in doing vigorous activities, such as running, lifting heavy objects, } \\
\text { participating in strenuous sports? }\end{array}$ \\
\hline 100 & PFA3 & Does your health now limit you in bending, kneeling, or stooping? \\
\hline 101 & PFA4 & $\begin{array}{l}\text { Does your health now limit you in doing heavy work around the house like scrubbing floors, } \\
\text { or lifting or moving heavy furniture? }\end{array}$ \\
\hline 102 & PFA5 & Does your health now limit you in lifting or carrying groceries? \\
\hline 103 & PFA6 & Does your health now limit you in bathing or dressing yourself? \\
\hline 104 & PFA7 & $\begin{array}{l}\text { How much do physical health problems now limit your usual physical activities } \\
\text { (such as walking or climbing stairs)? }\end{array}$ \\
\hline 105 & PFB1 & $\begin{array}{l}\text { Does your health now limit you in doing moderate work around the house like vacuuming, } \\
\text { sweeping floors or carrying in groceries? }\end{array}$ \\
\hline 106 & PFB3 & Does your health now limit you in putting a trash bag outside? \\
\hline 107 & PFB43 & Does your health now limit you in taking care of your personal needs (dress, comb hair, toilet, eat, bathe)? \\
\hline 108 & PFB44 & $\begin{array}{l}\text { Does your health now limit you in doing moderate activities, such as moving a table, pushing a vacuum cleaner, } \\
\text { bowling, or playing golf? }\end{array}$ \\
\hline 109 & PFB48 & Does your health now limit you in taking a shower? \\
\hline 110 & PFB49 & Does your health now limit you in going for a short walk (less than 15 minutes)? \\
\hline 111 & PFB5 & Does your health now limit you in hiking a couple of miles on uneven surfaces, including hills? \\
\hline 112 & PFB51 & Does your health now limit you in participating in active sports such as swimming, tennis, or basketball? \\
\hline 113 & PFB54 & Does your health now limit you in going OUTSIDE the home, for example to shop or visit a doctor's office? \\
\hline 114 & PFB7 & $\begin{array}{l}\text { Does your health now limit you in doing strenuous activities such as backpacking, skiing, playing tennis, } \\
\text { bicycling or jogging? }\end{array}$ \\
\hline 115 & PFC10 & Does your health now limit you in climbing several flights of stairs? \\
\hline 116 & PFC12 & Does your health now limit you in doing two hours of physical labor? \\
\hline 117 & PFC20 & Does your health now limit you in walking one hundred yards? \\
\hline 118 & PFC34 & Does your health now limit you in walking several hundred yards? \\
\hline 119 & PFC35 & Does your health now limit you in doing eight hours of physical labor? \\
\hline 120 & PFC36 & Does your health now limit you in walking more than a mile? \\
\hline 121 & PFC37 & Does your health now limit you in climbing one flight of stairs? \\
\hline 122 & PFC54 & Does your health now limit you in getting in and out of the bathtub? \\
\hline 123 & PFC56 & Does your health now limit you in walking about the house? \\
\hline $124 * * *$ & PFB50 & How much difficulty do you have doing your daily physical activities, because of your health? \\
\hline
\end{tabular}

*Response options for questions 1 - 98: 1 = Unable to do; 2 = With much difficulty; 3 = With some difficulty; 4 = With a little difficulty; 5 = Without any difficulty; **Response options for questions $99-123: 1=$ Cannot do; $2=$ Quite a lot; 3 = Somewhat; 4 = Very little; $5=$ Not at all; ***Response options for question 124: 1 = Can't do because of health, 2 = A lot of difficulty; 3 = Some difficulty; 4 = A little bit of difficulty; 5 = No difficulty at all; ****The original item identifier from the PROMIS item bank. 
Appendix 4. PROMIS item bank v. 1.0-depression.

\begin{tabular}{|c|c|c|}
\hline \multicolumn{3}{|r|}{ In the past 7 days... } \\
\hline Item Number & ID* & Items** \\
\hline 1 & PAININ1 & How difficult was it for you to take in new information because of pain? \\
\hline 1 & EDDEP04 & I felt worthless \\
\hline 2 & EDDEP05 & I felt that I had nothing to look forward to \\
\hline 3 & EDDEP06 & I felt helpless \\
\hline 4 & EDDEP07 & I withdrew from other people \\
\hline 5 & EDDEP09 & I felt that nothing could cheer me up \\
\hline 6 & EDDEP14 & I felt that I was not as good as other people \\
\hline 7 & EDDEP17 & I felt sad \\
\hline 8 & EDDEP19 & I felt that I wanted to give up on everything \\
\hline 9 & EDDEP21 & I felt that I was to blame for things \\
\hline 10 & EDDEP22 & I felt like a failure \\
\hline 11 & EDDEP23 & I had trouble feeling close to people \\
\hline 12 & EDDEP26 & I felt disappointed in myself \\
\hline 13 & EDDEP27 & I felt that I was not needed \\
\hline 14 & EDDEP28 & I felt lonely \\
\hline 15 & EDDEP29 & I felt depressed \\
\hline 16 & EDDEP30 & I had trouble making decisions \\
\hline 17 & EDDEP31 & I felt discouraged about the future \\
\hline 18 & EDDEP35 & I found that things in my life were overwhelming \\
\hline 19 & EDDEP36 & I felt unhappy \\
\hline 20 & EDDEP39 & I felt I had no reason for living \\
\hline 21 & EDDEP41 & I felt hopeless \\
\hline 22 & EDDEP42 & I felt ignored by people \\
\hline 23 & EDDEP44 & I felt upset for no reason \\
\hline 24 & EDDEP45 & I felt that nothing was interesting \\
\hline 25 & EDDEP46 & I felt pessimistic \\
\hline 26 & EDDEP48 & I felt that my life was empty \\
\hline 27 & EDDEP50 & I felt guilty \\
\hline 28 & EDDEP54 & I felt emotionally exhausted \\
\hline
\end{tabular}

*The original item identifier from the PROMIS item bank; **Response options for questions: 1 = Never; 2 = Rarely; 3 = Sometimes; 4 = Often; 5 = Always. 
Appendix 5. PROMIS item bank v1.0-pain interference.

\begin{tabular}{|c|c|c|}
\hline \multicolumn{3}{|r|}{ In the past 7 days... } \\
\hline Item Number & ID* & Items** \\
\hline 1 & PAININ1 & How difficult was it for you to take in new information because of pain? \\
\hline 2 & PAININ3 & How much did pain interfere with your enjoyment of life? \\
\hline 3 & PAININ5 & How much did pain interfere with your ability to participate in leisure activities? \\
\hline 4 & PAININ6 & How much did pain interfere with your close personal relationships? \\
\hline 5 & PAININ8 & How much did pain interfere with your ability to concentrate? \\
\hline 6 & PAININ9 & How much did pain interfere with your day to day activities? \\
\hline 7 & PAININ10 & How much did pain interfere with your enjoyment of recreational activities? \\
\hline 8 & PAININ11 & How often did you feel emotionally tense because of your pain? \\
\hline 9 & PAININ12 & How much did pain interfere with the things you usually do for fun? \\
\hline 10 & PAININ13 & How much did pain interfere with your family life? \\
\hline 11 & PAININ17 & How much did pain interfere with your relationships with other people? \\
\hline 12 & PAININ18 & How much did pain interfere with your ability to work (include work at home)? \\
\hline 13 & PAININ19 & How much did pain make it difficult to fall asleep? \\
\hline 14 & PAININ20 & How much did pain feel like a burden to you? \\
\hline 15 & PAININ22 & How much did pain interfere with work around the home? \\
\hline 16 & PAININ31 & How much did pain interfere with your ability to participate in social activities? \\
\hline 17 & PAININ34 & How much did pain interfere with your household chores? \\
\hline 18 & PAININ35 & $\begin{array}{l}\text { How much did pain interfere with your ability to make trips from home that kept you gone } \\
\text { for more than } 2 \text { hours? }\end{array}$ \\
\hline 19 & PAININ36 & How much did pain interfere with your enjoyment of social activities? \\
\hline 20 & PAININ48 & How much did pain interfere with your ability to do household chores? \\
\hline 21 & PAININ49 & How much did pain interfere with your ability to remember things? \\
\hline 22 & PAININ56 & How irritable did you feel because of pain? \\
\hline 23 & PAININ14 & $\begin{array}{l}\text { How much did pain interfere with doing your tasks away from home } \\
\text { (eg, getting groceries, running errands)? }\end{array}$ \\
\hline 24 & PAININ16 & How often did pain make you feel depressed? \\
\hline 25 & PAININ24 & How often was pain distressing to you? \\
\hline 26 & PAININ26 & How often did pain keep you from socializing with others? \\
\hline 27 & PAININ29 & How often was your pain so severe you could think of nothing else? \\
\hline 28 & PAININ32 & How often did pain make you feel discouraged? \\
\hline 29 & PAININ37 & How often did pain make you feel anxious? \\
\hline 30 & PAININ38 & How often did you avoid social activities because it might make you hurt more? \\
\hline 31 & PAININ39 & How often did pain make simple tasks hard to complete? \\
\hline 32 & PAININ40 & How often did pain prevent you from walking more than 1 mile? \\
\hline 33 & PAININ42 & How often did pain prevent you from standing for more than one hour? \\
\hline 34 & PAININ46 & How often did pain make it difficult for you to plan social activities? \\
\hline 35 & PAININ47 & How often did pain prevent you from standing for more than 30 minutes? \\
\hline 36 & PAININ50 & How often did pain prevent you from sitting for more than 30 minutes? \\
\hline 37 & PAININ51 & How often did pain prevent you from sitting for more than 10 minutes? \\
\hline 38 & PAININ52 & How often was it hard to plan social activities because you didn't know if you would be in pain? \\
\hline 39 & PAININ53 & How often did pain restrict your social life to your home? \\
\hline 40 & PAININ55 & How often did pain prevent you from sitting for more than one hour? \\
\hline 41 & PAININ54 & How often did pain keep you from getting into a standing position? \\
\hline
\end{tabular}

*The original item identifier from the PROMIS item bank; **Response options for questions: 1 = Not at all; 2 = A little bit; 3 = Somewhat; 4 = Quite a bit; 5 = Very much. 